\title{
Diabetes in Primary Care: Prospective Associations between Depression, Nonadherence and Glycemic Control
}

\author{
Jörg Dirmaier ${ }^{\mathrm{a}}$ Birgit Watzke ${ }^{\mathrm{a}}$ Uwe Koch $^{\mathrm{a}}$ Holger Schulz $^{\mathrm{a}}$ Hendrik Lehnert ${ }^{\mathrm{b}, \mathrm{d}}$ \\ Lars Pieper ${ }^{c}$ Hans-Ulrich Wittchen ${ }^{c}$ \\ a Department of Medical Psychology, University Medical Center Hamburg-Eppendorf, Hamburg, \\ ${ }^{b}$ First Department of Medicine, University of Lübeck, Lübeck, and ' Institute of Clinical Psychology and \\ Psychotherapy, Center of Clinical Epidemiology and Longitudinal Studies (CELOS), Technische Universität \\ Dresden, Dresden, Germany; ${ }^{\text {d} W a r w i c k ~ M e d i c a l ~ S c h o o l, ~ U n i v e r s i t y ~ H o s p i t a l ~ o f ~ C o v e n t r y, ~ C o v e n t r y, ~ U K ~}$
}

\section{Key Words}

Diabetes $\cdot$ Nonadherence $\cdot$ Glycemic control

\begin{abstract}
Background: Findings are inconsistent regarding the degree to which depression may exert a negative impact on glycemic control in patients with type 2 diabetes. We therefore aimed to examine the longitudinal relationship between depression, behavioral factors, and glycemic control. Methods: In a prospective component of a nationally representative sample, 866 patients with type 2 diabetes aged $\geq 18$ years completed a standardized assessment including a laboratory screening, questionnaires, and diagnostic measures. Subsequent to baseline $\left(t_{0}\right)$, patients were tracked over a period of 12 months $\left(t_{1}\right)$. Depression was assessed according to DSM-IV and ICD-10 criteria. Glycemic control was determined by levels of glycosylated hemoglobin $\left(\mathrm{HbA}_{1 \mathrm{c}}\right)$; a level of $\geq 7 \%$ was judged as unsatisfactory. Regression analyses were performed to analyze the prospective relationship between depression, medication adherence, diabetes-related health behavior, and $\mathrm{HbA}_{1 \mathrm{c}}$. Results: Patients with depression at $t_{0}$ revealed increased rates of medication non-
\end{abstract}

adherence (adjusted OR: $2.67 ; \mathrm{Cl}: 1.38-5.15)$ at $\mathrm{t}_{1}$. Depression (adjusted regression coefficient: $\beta=0.96 ; p=0.001$ ) and subthreshold depression $(\beta=1.01 ; p<0.001)$ at $t_{0}$ also predicted increased problems with diabetes-related health behavior at $\mathrm{t}_{1}$. Adjusted ORs for poor glycemic control $\left(\mathrm{HbA}_{1 \mathrm{c}} \geq 7 \%\right)$ at $\mathrm{t}_{1}$ were also increased for patients with baseline depression (2.01; Cl: 1.10-3.69). However, problems with medication adherence as well as problems with diabetes-related health behavior at $\mathrm{t}_{0}$ did not predict poor glycemic control at $\mathrm{t}_{1}$. Conclusions: In a prospective representative study of patients with type 2 diabetes, baseline depression predicted problems with medication adherence, problems with health-related behaviors, and unsatisfactory glycemic control at follow-up.

Copyright $\odot 2010$ S. Karger AG, Basel

\section{Introduction}

There is a two- to three-fold risk of depression in patients with type 2 diabetes, suggesting that depression is strongly related to this disease [1]. Comorbid depression in diabetes was thereby found to be associated with in-

\section{KARGER}

Fax +41613061234 E-Mail karger@karger.ch www.karger.com
(C) 2010 S. Karger AG, Base

$0033-3190 / 10 / 0793-0172 \$ 26.00 / 0$

Accessible online at:

www.karger.com/pps
Dr. Jörg Dirmaier

Department of Medical Psychology, Medical Center Hamburg-Eppendorf

Martinistrasse 52, Building S 35

DE-20246 Hamburg (Germany)

Tel. +49 4042803 9137, Fax +49 4042803 4940, E-Mail dirmaier@uke.uni-hamburg.de 
creased instances and severities of medical complications [2], poorer overall health status [3], more absences from work [4], higher health care costs [5], and increased mortality [6], as opposed to diabetes without depression.

Recent research suggests a bidirectional association between diabetes and depression [7]. However, the biological and behavioral mechanisms of this association remain unclear [8]. In addition to the direct negative physiological effects on glucose metabolism (activation of the neuroendocrine and inflammatory responses [9]) and behavioral risk factors such as obesity-promoting health behaviors (e.g. physical inactivity, hypercaloric diets), depression produces an especially poor adherence to a variety of self-care responsibilities (e.g. medications or modification of health behaviors), which is considered to be related to the state of glycemic control [10].

High glycosylated hemoglobin $\left(\mathrm{HbA}_{1 \mathrm{c}}\right)$ is an index of long-term glycemic control and an independent predictor of diabetes. High levels of $\mathrm{HbA}_{1 \mathrm{c}}$ are associated with an increased risk of medical complications, mortality, and poor quality of life in patients with type 2 diabetes [11]. However, previous results regarding the association of depression and $\mathrm{HbA}_{1 \mathrm{c}}$ in patients with type 2 diabetes are inconsistent [12-14], which is surprising in light of the strong association between depression and diabetes. Moreover, in the field of primary care, these studies have been cross-sectional.

Given these inconsistent results and the lack of prospective examinations of the effect of depression on $\mathrm{HbA}_{1 \mathrm{c}}$ and relevant behavioral mechanisms (adherence to medications and health behaviors) linking these associations, we used a nationally representative sample of primary care patients with type 2 diabetes to investigate: (1) the effects of depression on adherence to medical recommendations (concerning medication and health behavior), and (2) the effects of depression and adherence to medical recommendations (concerning medication and health behavior) on $\mathrm{HbA}_{1 \mathrm{c}}$ in primary care patients with type 2 diabetes over a 12 -month follow-up period.

\section{Patients and Methods}

\section{Sample}

Analyses were based on the DETECT (Diabetes Cardiovascular Risk Evaluation: Targets and Essential Data for Commitment of Treatment) study, which is a cross-sectional clinical-epidemiological study with a prospective-longitudinal component in primary care in Germany. Data collection was performed between September 2003 and December 2004. A complete description of the study methodology and sampling has been published elsewhere [15].

Depression, Adherence and Glycemic Control
In brief, the DETECT study used a random subsample of 7,519 patients of the core survey, which consisted of 55,518 unselected consecutive patients (aged $\geq 18$ years) attending 3,188 primary care settings at baseline $\left(\mathrm{t}_{0}\right)$. It utilized a standardized assessment, including questionnaires for patients and physicians, and an extensive laboratory screening program with follow-up $\left(t_{1}\right)$ after 12 months. At $t_{1}$, data from 6,627 (93.1\%) patients were collected, including 866 patients attending 466 different primary care settings who had been diagnosed with type 2 diabetes and had a valid score for depression.

In the later analyses, the data were weighted to adjust for the regional distribution of general practitioners and internists to obtain a representative sample of German primary care patients. The study sample of doctors can therefore be regarded as nationally representative in terms of regional distribution, age, years of experience, specialty orientation, and patient load per day [15]. The longitudinally investigated cohort was additionally adjusted to the morbidity status, age, and gender distribution of the main study. Moreover, there were no noteworthy differences in the characteristics of those patients analyzed only at baseline and the subsample followed up for 1 year [15]. The 866 patients for whom a valid score for depression was available did not differ from the 917 patients diagnosed with type 2 diabetes with regard to sociodemographic or clinical variables. Therefore, the patient sample can also be regarded as representative of primary care settings in Germany [15].

The study was approved by the local ethics committee of the Technical University Dresden (AZ: EK149092003; 16.09.2003).

\section{Assessment of Depression}

The Depression Screening Questionnaire (DSQ) developed by Wittchen and Perkonigg [16] is a well-established and frequently used instrument in large-scale studies in primary care [17]. This self-report measure consists of 10 items with a 3-point scale with 0 (never) through 1 (on some days) to 2 (on the majority of days) referring to the preceding 2 weeks. The diagnosis of depression can be made according to the ICD-10 criteria: at least 3 questions must be answered with 'on the majority of days' and the total score must be $>7$. The DSQ has a high internal consistency (Cronbach's $\alpha=0.83$ [18]), and the 1-week test-retest reliability found a $\kappa$ value of 0.82 [16]. The validity of the diagnosis of major depression is very high compared to the Composite International Diagnostic Interview [19]: $\kappa=0.89$ for DSM-IV and $\kappa=0.84$ for ICD-10 [16]. In order to account for recent findings showing that subthreshold levels of depression also have a negative impact on health outcomes in patients with type 2 diabetes [20], the calculated total scores were grouped into 3 categories: $0-4$ points indicated no depression, 5-7 points indicated subthreshold depression, and $>7$ points indicated depression. The cut-off of $\leq 4$ points was chosen for patients whose depressive symptomatology is not sufficient for the subthreshold category, taking into account 4 'somatic' items that diabetic patients might experience due to resulting physical limitations (psychomotor retardation, sleep disturbance, loss of sexual desire, loss of appetite or weight loss).

\section{Assessment of Adherence}

Medication nonadherence was assessed by responses to the question 'How often did you have problems taking your medications as prescribed by the physician?' based on a 4-level response scale (almost never/rarely/often/always) during the last 4 weeks. 
Due to skewed data, the values were split into 2 categories: 'nearly never' versus 'rarely/often/always'. Nonadherence with health behavior during the preceding 4 weeks was assessed by 5 items covering the frequency of problems with diet ( 2 items: healthy diet plans, weight control/reduction), stopping smoking, alcohol consumption, and adequate physical activity, with 4 response possibilities (never/rarely/often/almost daily). The values were added to a total score. Both assessments (adherence to medication/ health behaviors) have high face validity as they directly capture observable behavior patterns.

Assessment of Diabetes and $\mathrm{Hb} \mathrm{A}_{1 c}$

Type 2 diabetes was assumed when the diagnosis was rated as 'definite' (vs. 'suspected' or 'no') in the questionnaire answered by the physicians. $\mathrm{HbA}_{1 \mathrm{c}}$ values were used as an indicator of glycemic control. The general goal in the treatment of diabetes is a $\mathrm{HbA}_{1 \mathrm{c}}$ of $<7 \%$ [21]. Therefore, $\mathrm{HbA}_{1 \mathrm{c}}$ values were classified as $\geq 7 \%$ (unsatisfactory glycemic control) and as $<7 \%$ (good glycemic control).

\section{Statistical Analysis}

$\chi^{2}$ or $\mathrm{t}$ tests were used to test for differences between type 2 diabetes patients with various levels of depression.

Logistic regression was used to analyze the effects of depression on problems with medication adherence and glycemic control. Linear regression models were employed to investigate the influence of depression on problems with health behavior. The odds ratios (ORs) and the regression coefficients $(\beta)$ were calculated with 95\% CI. All models were adjusted for gender, age, marital and employment status, education, physical activity, BMI, smoking, drinking, duration of diabetes, and type of diabetes treatment.

Adjustments were also made to account for the stratified sampling design and the resulting possibility of clustered observations: patients may be clustered in primary care units so that correlations within these units can be assumed. Therefore, we calculated CIs for all regression analyses applying the Huber-White sandwich method [22].

Power calculations ( $\chi^{2}$ test of trend in proportions based on the logistic model) revealed that given a sample size of $866(\alpha=$ 0.05 , two-sided), an OR of 2 for poor glycemic control is detectable with a power of $91 \%$. For all analyses, the level of significance was set at $\mathrm{p}<0.05$. We employed the statistical package STATA 9.1.

\section{Results}

For the prospective cohort study, the sociodemographic, behavioral, and clinical characteristics of the type 2 diabetes patients with no depression, subthreshold depression, or depression are compared in table 1. A total of 179 patients $(20.7 \%)$ had subthreshold depression, and $102(11.7 \%)$ of the 866 patients suffered from depression. Compared to patients with no depression, patients with depression as well as patients with subthreshold depression were more frequently women with fewer weekly physical activities. Furthermore, patients with depres- sion were younger, more likely to be smokers, less likely to drink alcohol, and were more often treated with insulin compared to patients with no depression. Patients with depression were also younger and more likely to be smokers than patients with subthreshold depression.

\section{Association of Depression, Medication Adherence, and Health Behavior at Baseline}

At baseline, when adjusting for the covariates listed in table 1, patients with depression exhibited a higher risk $(\mathrm{OR}=4.45 ; \mathrm{CI}: 2.52-7.84 ; \mathrm{p}<0.001)$ of problems with medication adherence. Unfavorable health behavior was associated with subthreshold depression $(\beta=0.68$; CI: 0.29-1.08) and depression ( $\beta=1.47$; CI: $0.96-1.98 ; \mathrm{R}^{2}=$ $0.41)$ at baseline. Having subthreshold depression was not associated with glycemic control at baseline. However, among those who had depression, the odds of problems with glycemic control at baseline were elevated $(\mathrm{OR}=$ 1.71; CI: 1.01-2.90; p < 0.05). There were no associations between glycemic control and having problems with medication adherence or health behavior.

\section{Prediction of Glycemic Control, Medication \\ Adherence, and Health Behavior}

The prospective association between depression $\left(t_{0}\right)$ and medication adherence and health behavior at followup $\left(\mathrm{t}_{1}\right)$ is shown in table 2 . Having subthreshold depression $\left(t_{0}\right)$ is not associated with medication adherence problems at $t_{1}$. However, among those who had depression, the odds of problems with medication adherence (adjusted for all covariates listed in table 1) are elevated at $\mathrm{t}_{1}(\mathrm{OR}=2.67 ; \mathrm{CI}: 1.38-5.15 ; \mathrm{p}=0.003)$. Table 2 also shows the crude and adjusted standardized regression coefficients for the association of depression $\left(\mathrm{t}_{0}\right)$ and problems with health behavior $\left(t_{1}\right)$. In the adjusted model, having more problems with health behavior is associated with harboring subthreshold depression ( $\beta=1.01$; CI: $0.62-$ $1.40)$ and depression ( $\beta=0.96$; CI: $\left.0.40-1.52 ; \mathrm{R}^{2}=0.30\right)$ at baseline.

The association between depression $\left(\mathrm{t}_{0}\right)$ and $\mathrm{HbA}_{1 \mathrm{c}}$ at $t_{1}$ is also shown in table 2 . Having subthreshold depression $\left(t_{0}\right)$ is not associated with glycemic control at $t_{1}$. However, among those who were classified as depressed, the adjusted odds of problems with glycemic control are elevated at $\mathrm{t}_{1}(\mathrm{OR}=2.01 ; \mathrm{CI}: 1.10-3.69 ; \mathrm{p}=0.023)$. These analyses were also run separately for the association of medication adherence and health behavior $\left(\mathrm{t}_{0}\right)$ on glycemic control at $t_{1}$. After adjusting for the covariates, there are no significant associations between problems with medication adherence and health behavior $\left(\mathrm{t}_{0}\right)$ and prob- 
Table 1. Sociodemographic and clinical baseline characteristics of primary care patients by severity of depres$\operatorname{sion}(\mathrm{n}=866)$

\begin{tabular}{|c|c|c|c|}
\hline Variables & $\begin{array}{l}\text { No depression } \\
(\mathrm{n}=585)\end{array}$ & $\begin{array}{l}\text { Subthreshold } \\
\text { depression }(\mathrm{n}=179)\end{array}$ & $\begin{array}{l}\text { Depression } \\
(\mathrm{n}=102)\end{array}$ \\
\hline Female gender & $266(45.5)$ & $100(55.6)^{\mathrm{a}}$ & $57(55.9)^{\mathrm{a}}$ \\
\hline Age, years & $66.8 \pm 9.7$ & $66.8 \pm 10.0$ & $63.5 \pm 11.9^{\mathrm{b}, \mathrm{d}}$ \\
\hline Years of education & $9.2 \pm 1.9$ & $9.2 \pm 1.7$ & $9.2 \pm 1.8$ \\
\hline \multicolumn{4}{|l|}{ Marital status } \\
\hline Single & $24(4.2)$ & $10(5.7)$ & $6(5.9)$ \\
\hline Married & $400(69.6)$ & $110(62.5)$ & $67(66.3)$ \\
\hline Divorced/widowed & $151(26.3)$ & $56(31.8)$ & $28(27.7)$ \\
\hline Retired/unemployed/housewife & $480(82.9)$ & $161(90.4)^{\mathrm{a}}$ & $90(89.1)$ \\
\hline Smoking & & & \\
\hline Nonsmoker & $463(87.4)$ & $147(89.1)$ & $78(83.0)$ \\
\hline Smoker & $67(12.6)$ & $18(10.9)$ & $16(17.0)$ \\
\hline \multicolumn{4}{|l|}{ Amount of drinking } \\
\hline Less than 2 times a month & $267(48.5)$ & $94(54.7)$ & $68(68.7)$ \\
\hline Less than 2 times a week & $111(20.1)$ & $37(21.5)$ & $14(14.1)$ \\
\hline 3 or more times a week & $137(31.4)$ & $41(23.8)$ & $17(17.2)$ \\
\hline BMI & $29.4 \pm 4.7$ & $30.1 \pm 5.1$ & $30.5 \pm 5.8$ \\
\hline Weekly physical activities $<2 \mathrm{~h}$ & $161(30.1)$ & $75(46.3)^{\mathrm{c}}$ & $41(47.7)^{\mathrm{c}}$ \\
\hline Duration of diabetes, years & $7.6 \pm 6.7$ & $8.6 \pm 7.7$ & $8.4 \pm 7.4$ \\
\hline \multicolumn{4}{|l|}{ Diabetes treatment } \\
\hline None or diet & $169(28.9)$ & $46(25.6)$ & $29(28.7)$ \\
\hline Oral hypoglycemic & $352(60.2)$ & $104(57.8)$ & $51(50.5)$ \\
\hline Insulin or insulin + oral hypoglycemic & $64(10.9)$ & $30(16.7)$ & $21(20.8)$ \\
\hline
\end{tabular}

Data are presented as means $\pm \mathrm{SD}$ or number of patients with percentages in parentheses.

${ }^{\mathrm{a}} \mathrm{p}<0.05,{ }^{\mathrm{b}} \mathrm{p}<0.01,{ }^{\mathrm{c}} \mathrm{p}<0.001$ vs. no depression, ${ }^{\mathrm{d}} \mathrm{p}<0.01$ vs. subthreshold depression.

Table 2. OR for problems with medication adherence and glycemic control, and standardized regression coefficients ( $\beta$ ) for problems with health behavior

\begin{tabular}{|c|c|c|c|c|c|c|c|c|c|c|c|c|}
\hline & \multicolumn{4}{|c|}{ Problems with medication adherence $\left(t_{1}\right)$} & \multicolumn{4}{|c|}{ Problems with health behavior $\left(t_{1}\right)$} & \multicolumn{4}{|c|}{ Problems with glycemic control ${ }^{1}\left(t_{1}\right)$} \\
\hline & OR crude & $\mathrm{p}$ & OR adjusted ${ }^{2}$ & $\mathrm{p}$ & $\beta$ crude & $\mathrm{p}$ & $\beta$ adjusted $^{2}$ & $\mathrm{p}$ & OR crude & $\mathrm{p}$ & OR adjusted ${ }^{2}$ & $\mathrm{p}$ \\
\hline No depression $\left(\mathrm{t}_{0}\right)$ & ref. & & ref. & & ref. & & ref. & & ref. & & ref. & \\
\hline $\begin{array}{l}\text { Subthreshold } \\
\text { depression }\left(\mathrm{t}_{0}\right)\end{array}$ & $\begin{array}{l}1.4 \\
(1.0-2.2)\end{array}$ & 0.14 & $\begin{array}{l}1.2 \\
(0.7-2.1)\end{array}$ & 0.43 & $\begin{array}{l}1.1 \\
(0.7-1.6)\end{array}$ & $<0.001$ & $\begin{array}{l}1.0 \\
(0.6-1.4)\end{array}$ & $<0.001$ & $\begin{array}{l}0.9 \\
(0.6-1.3)\end{array}$ & 0.65 & $\begin{array}{l}0.7 \\
(0.4-1.1)\end{array}$ & 0.17 \\
\hline Depression $\left(\mathrm{t}_{0}\right)$ & $\begin{array}{l}2.9 \\
(1.7-4.8)\end{array}$ & $<0.001$ & $\begin{array}{l}2.7 \\
(1.4-5.1)\end{array}$ & 0.003 & $\begin{array}{l}1.3 \\
(0.7-1.9)\end{array}$ & $<0.001$ & $\begin{array}{l}1.0 \\
(0.4-1.5)\end{array}$ & 0.001 & $\begin{array}{l}2.1 \\
(1.4-3.2)\end{array}$ & $<0.001$ & $\begin{array}{l}2.0 \\
(1.1-3.7)\end{array}$ & 0.02 \\
\hline $\begin{array}{l}\text { Problems with medica- } \\
\text { tion adherence }\left(t_{0}\right)\end{array}$ & & & & & & & & & $\begin{array}{l}1.4 \\
(1.0-2.1)\end{array}$ & 0.07 & $\begin{array}{l}1.3 \\
(0.9-2.0)\end{array}$ & 0.21 \\
\hline $\begin{array}{l}\text { Problems with } \\
\text { health behavior }\left(\mathrm{t}_{0}\right)\end{array}$ & & & & & & & & & $\begin{array}{l}1.0 \\
(1.0-1.1)\end{array}$ & 0.18 & $\begin{array}{l}1.0 \\
(0.9-1.1)\end{array}$ & 0.84 \\
\hline
\end{tabular}

95\% CI are given in parentheses.

${ }^{1} \mathrm{HbA}_{1 \mathrm{c}} \geq 7 \% .{ }^{2}$ Adjusted for gender, age, marital and employment status, education, physical activity, BMI, smoking, drinking, duration of diabetes, and type of diabetes treatment. 
lems with glycemic control at $t_{1}$. The association of medication adherence and health behavior $\left(t_{0}\right)$ on glycemic control at $t_{1}$ was additionally tested for the subsample of insulin-treated diabetics. Again, there are no significant associations between problems with medication adherence (OR: 1.31; CI: $0.86-1.98 ; \mathrm{p}=0.210$ ) and health behavior (OR: 0.99; CI: 0.91-1.08; $\mathrm{p}=0.844$ ) at $\mathrm{t}_{0}$ and problems with glycemic control at $\mathrm{t}_{1}$.

\section{Discussion}

As depressive symptoms occur frequently in patients with type 2 diabetes, it is important to understand how depression affects the treatment of diabetes. Therefore, we analyzed a large sample to assess prospective associations between depression, adherence, and glycemic control in patients with type 2 diabetes.

This study showed that depression, but not subthreshold depression, is prospectively associated with higher $\mathrm{HbA}_{1 \mathrm{c}}$ levels over a 12-month follow-up. To our knowledge, this is the first study using a nationally representative cohort of adults in primary health care systems that showed a prospective relationship between depression and glycemic control.

It is still uncertain from current research whether coexisting depression affects glycemic control. Our study found that for patients with type 2 diabetes and co-existing depression at baseline, the odds of $\mathrm{HbA}_{1 \mathrm{c}} \geq 7 \%$ versus $\mathrm{HbA}_{1 \mathrm{c}}<7 \%$ at follow-up were doubled, even when various other factors were controlled. This study thus confirmed existing findings from studies using cross-sectional designs indicating that depression is related to glycemic control [23]. In accordance with prior research [24], there was no prospective relationship between subthreshold depression and both medication adherence and $\mathrm{HbA}_{1 \mathrm{c}}$ levels. As shown by Fisher et al. [25], subthreshold or nonclinical levels of depression are more strongly correlated with sources of distress resulting from diabetes specifically, such as diabetes-related health care and economic, social, and family difficulties [25], than with clinical depression. This could be a possible reason for the lack of associations between subthreshold depression and $\mathrm{HbA}_{1 \mathrm{c}}$ levels.

Depression at baseline predicts more problems with medication adherence and health behavior at follow-up among patients with type 2 diabetes. According to Cramer [26], medication adherence is defined as 'the extent to which a patient acts in accordance with the prescribed interval and dose of a dosing regimen', whereas medica- tion persistence is defined as 'the duration of time from initiation to discontinuation of therapy'. Our findings regarding adherence to medication and health behavior are consistent with previous cross-sectional research $[23,27]$. Additionally, earlier research has shown that even subclinical levels of depression are associated with nonadherence [10], although again only cross-sectionally. Our study thus confirms these findings through a prospective study design, which indicates that even low levels of depressive symptomatology represent a major prognostic risk factor for poor medication adherence and poor health behavior.

Adherence to self-care behavior - like medication intake, dietary guidelines, or exercise - is crucial in the treatment of diabetes and appears to be an important contributor to glycemic control [27]. Inconsistent with these findings, adherence to medication and health behavior at baseline did not predict problems with glycemic control $\left(\mathrm{HbA}_{1 \mathrm{c}}\right.$ level $\geq 7 \%$ ). This may be a function of different or imprecise methodology for measuring adherence (e.g. single-item measurement of medication adherence), differences in the complexity of self-care regiments, different study designs, and social desirability or recall biases. In addition, our data show that there are low baseline values for medication adherence as well as health behavior, which might result from sample-specific characteristics such as older age and long duration and treatment of diabetes. Being treated for diabetes for several years might have improved medication adherence, and, with older age, the subjective standard for health behavior might decrease. Thus, the variable probably did not provide enough variance in its distribution. It is also possible that adherence and health behavior improved over the course of the year, e.g. due to interventions of the responsible physician. Furthermore, previous research has shown that the strongest associations between adherence and glycemic control exist in insulin-treated diabetic patients [28], and focusing on this subsample may have revealed a stronger relationship. Testing this hypothesis did not show any significant results, however, probably because the proportion of subjects with insulin treatment was comparatively low [23] in our patients.

Several limitations relevant to interpreting the findings have to be mentioned. One limitation was the use of self-report data on medication adherence and health behavior, because of a resulting tendency to overestimate adherence due to recall biases and social desirability. However, a meta-analysis comparing self-report measures with more objective methods such as electronic monitoring showed that self-report measurements have 
sufficient validity and reliability [29]. In addition, electronic monitoring is associated with high costs and therefore not appropriate in large-scale studies. Second, measuring medication adherence with a single item represents another limitation of the study. Yet there are some indications that single-item measurement has sufficient predictive value and concordance with scales including multiple items to measure adherence [30]. Third, we did not have any measurements for diabetes-specific selfcare, such as self-monitoring of blood glucose, foot care or dietary habits. This was due to the study design, in which data for several chronic diseases were collected, which prevented the use of diabetes-specific instruments. Moreover, there was no data on the course or treatment of depression during the 12-month follow-up period. However, depression has been shown to be persistent in nearly three quarters of diabetic adults at 6-month follow-up [31], which is consistent with our data where depression was persistent over the 12-month follow-up period in half of the patients. Because depression among primary care patients with diabetes is predominantly unrecognized and untreated, the findings probably would be similar even when treatment was accounted for. During a 12-month period, less than half of the patients with depression were recognized, less than half of them received antidepressant descriptions, and only about $7 \%$ received adequate psychotherapeutic treatment [32]. By comparison, in our sample merely one third of the depressed patients were recognized as depressed by their physicians, and therefore the rate of depression-related treatment is presumed to be correspondingly low. Measuring depression with the DSQ may have resulted in an overestimation of depressive symptoms because diabetes and other medical comorbidities in primary care frequently involve somatic symptoms that were probably attributed to depression. However, the $11.8 \%$ rate of major depression found in this sample is even lower than the overall prevalence of depression in patients with diabetes of $17.6 \%$ found in a prior meta-analysis [1]. Nevertheless, cross-validation in diabetic patients with a well-validated screening instrument for depression for the use in primary care settings may additionally be required.

This study has several major strengths. First, the studied sample constituted a large nationally representative cohort of adults in primary health care. Therefore, the generalizability of the results to countries providing similar health care services is very high. Second, its prospective study design enables causal inferences regarding $\mathrm{HbA}_{1 \mathrm{c}}$ levels and depression. Third, the study combined multiple data perspectives resulting in a broad frame- work; self-reports, data collected from the physician, and the availability of laboratory data $\mathrm{HbA}_{1 c}$ provided a large number of diabetes-related variables.

In conclusion, the results of this study of adults with type 2 diabetes show that there is a significant prospective relationship between depression and glycemic control, indexed by $\mathrm{HbA}_{1 \mathrm{c}}$, and that even subthreshold depression is associated to problems with adherence to treatment recommendations over a 12-month follow-up. These data clearly emphasize the importance of depression in the treatment of adults with type 2 diabetes.

\section{Appendix: DETECT Members}

Principal investigator: Prof. Dr. H.-U. Wittchen. Staff members: Dipl. Psych. L. Pieper, Dipl. Math. J. Klotsche, Dipl. Psych. T. Eichler, Dipl. Psych. Dr. H. Glaesmer, E. Katze, Dipl. Psych. A. Bayer, Dipl. Psych. A. Neumann. Steering board: Prof. Dr. H. Lehnert (Lübeck, Coventry), Prof. Dr. G.K. Stalla (München), Prof. Dr. M.A. Zeiher (Frankfurt) Prof. Dr. M. Wehling (Mannheim). Advisory board: Prof. Dr. W. März (Graz/Heidelberg), Prof. Dr. S. Silber (München), Prof. Dr. U. Koch (Hamburg), PD Dr. D. Pittrow (München/Dresden).

\section{Acknowledgement}

DETECT (Diabetes Cardiovascular Risk Evaluation: Targets and Essential Data for Commitment of Treatment) is supported by an unrestricted educational grant from Pfizer, Karlsruhe, Germany.

References

1 Ali S, Stone M, Peters J, Davies M, Khunti K: The prevalence of comorbid depression in adults with type 2 diabetes: a systematic review and meta-analysis. Diabet Med 2006; 11:1165-1173.

-2 de Groot M, Anderson R, Freedland KE, Clouse RE, Lustman PJ: Association of depression and diabetes complications: a metaanalysis. Psychosom Med 2001;63:619-630.

-3 Moussavi S, Chatterji S, Verdes E, Tandon A, Patel V, Ustun B: Depression, chronic diseases, and decrements in health: results from the World Health Surveys. Lancet 2007;370: 851-858.

-4 Kivimaki M, Vahtera J, Pentti J, Virtanen M, Elovainio M, Hemingway H: Increased sickness absence in diabetic employees: what is the role of co-morbid conditions? Diabet Med 2007;24:1043-1048.

5 Simon GE, Katon WJ, Lin EH, Ludman E, VonKorff M, Ciechanowski P, Young BA: Diabetes complications and depression as predictors of health service costs. Gen Hosp Psychiatry 2005;27:344-351. 
6 Katon W, Fan MY, Unutzer J, Taylor J, Pincus $\mathrm{H}$, Schoenbaum M: Depression and diabetes: a potentially lethal combination. J Gen Intern Med 2008;23:1571-1575.

$\checkmark 7$ Golden SH, Lazo M, Carnethon M, Bertoni AG, Schreiner PJ, Roux AV, Lee HB, Lyketsos $\mathrm{C}$ : Examining a bidirectional association between depressive symptoms and diabetes. JAMA 2008;299:2751-2759.

8 Knol MJ, Heerdink ER, Egberts AC, Geerlings MI, Gorter KJ, Numans ME, Grobbee $\mathrm{DE}$, Klungel $\mathrm{OH}$, Burger $\mathrm{H}$ : Depressive symptoms in subjects with diagnosed and undiagnosed type 2 diabetes. Psychosom Med 2007;69:300-305.

-9 Musselman DL, Betan E, Larsen H, Phillips LS: Relationship of depression to diabetes types 1 and 2: epidemiology, biology, and treatment. Biol Psychiatry 2003;54:317-329.

-10 Gonzalez JS, Safren SA, Cagliero E, Wexler DJ, Delahanty L, Wittenberg E, Blais MA, Meigs JB, Grant RW: Depression, self-care, and medication adherence in type 2 diabetes: relationships across the full range of symptom severity. Diabetes Care 2007;30:22222227.

11 Intensive blood-glucose control with sulphonylureas or insulin compared with conventional treatment and risk of complications in patients with type 2 diabetes (UKPDS 33). UK Prospective Diabetes Study (UKPDS) Group. Lancet 1998;352:837-853.

$>12$ Trief PM, Morin PC, Izquierdo R, Teresi J, Eimicke JP, Goland R, Starren J, Shea S, Weinstock RS: Depression and glycemic control in elderly ethnically diverse patients with diabetes: the IDEATel project. Diabetes Care 2006;29:830-835.

$\checkmark 13$ Engum A, Mykletun A, Midthjell K, Holen A, Dahl AA: Depression and diabetes: a large population-based study of sociodemographic, lifestyle, and clinical factors associated with depression in type 1 and type 2 diabetes. Diabetes Care 2005;28:1904-1909.

-14 Lustman PJ, Anderson RJ, Freedland KE, de Groot M, Carney RM, Clouse RE: Depression and poor glycemic control: a meta-analytic review of the literature. Diabetes Care 2000;23:934-942.
15 Wittchen HU, Glaesmer H, März W, Stalla G, Lehnert H, Zeiher AM, Silber S, Koch U, Böhler S, Pittrow D, Ruf G: Cardiovascular risk factors in primary care: methods and baseline prevalence rates - the DETECT program. Curr Med Res Opin 2005;21:619-629.

16 Wittchen HU, Perkonigg A: DIA-X-Screening Instruments: Questionnaire DIA-SSQ Screening for Mental Disorders; Questionnaire DIA-ASQ: Screening for Anxiety Disorders; Questionnaire DIA-DSQ: Screening for Depression (in German). Frankfurt, Swets and Zeitlinger, 1997.

-17 Munk-Jorgensen P, Allgulander C, Dahl AA, Foldager L, Holm M, Rasmussen I, Virta A, Huuhtanen MT, Wittchen HU: Prevalence of generalized anxiety disorder in general practice in Denmark, Finland, Norway, and Sweden. Psychiatr Serv 2006;57:1738-1744.

18 Höfler M, Wittchen H: Why do primary care doctors diagnose depression when diagnostic criteria are not met? Int J Methods Psychiatr Res 2000;9:110-120.

19 World Health Organization: Composite International Diagnostic Interview (CIDI) 1.0. Geneva, WHO, 1990.

20 Black SA, Markides KS, Ray LA: Depression predicts increased incidence of adverse health outcomes in older Mexican Americans with type 2 diabetes. Diabetes Care 2003;26:2822-2828.

21 American Diabetes Association: Standards of medical care in diabetes - 2006. Diabetes Care 2006;29(suppl 1):S4-S42.

22 Royall RM: Model robust confidence intervals using maximum likelihood estimators. Int Stat Rev 1986;54:221-227.

23 Katon W, von Korff M, Ciechanowski P, Russo J, Lin E, Simon G, Ludman E, Walker E, Bush T, Young B: Behavioral and clinical factors associated with depression among individuals with diabetes. Diabetes Care 2004 27:914-920.
24 Gross R, Olfson M, Gameroff MJ, Carasquillo O, Shea S, Feder A, Lantigua R, Fuentes M, Weissman MM: Depression and glycemic control in Hispanic primary care patients with diabetes. J Gen Intern Med 2005;20: 460-466.

25 Fisher L, Skaff MM, Mullan JT, Arean P, Mohr D, Masharani U, Glasgow R, Laurencin G: Clinical depression versus distress among patients with type 2 diabetes: not just a question of semantics. Diabetes Care 2007; 30:542-548.

-26 Cramer JA, Roy A, Burrell A, Fairchild CJ, Fuldeore MJ, Ollendorf DA, Wong PK: Medication compliance and persistence: terminology and definitions. Value Health 2008; 11:44-47.

27 Ciechanowski PS, Katon WJ, Russo JE, Hirsch IB: The relationship of depressive symptoms to symptom reporting, self-care and glucose control in diabetes. Gen Hosp Psychiatry 2003;25:246-252.

-28 Kravitz RL, Hays RD, Sherbourne CD, DiMatteo MR, Rogers WH, Ordway L, Greenfield S: Recall of recommendations and adherence to advice among patients with chronic medical conditions. Arch Intern Med 1993;153:1869-1878.

29 Garber MC, Nau DP, Erickson SR, Aikens JE, Lawrence JB: The concordance of self-report with other measures of medication adherence: a summary of the literature. Med Care 2004;42:649-652.

$>30$ Cook CL, Perri M 3rd: Single-item versus multiple-item measures of stage of change in compliance with prescribed medications. Psychol Rep 2004;94:115-124.

-31 Peyrot M, Rubin RR: Persistence of depressive symptoms in diabetic adults. Diabetes Care 1999;22:448-452.

>32 Katon WJ, Simon G, Russo J, Von Korff M, Lin EH, Ludman E, Ciechanowski P, Bush T: Quality of depression care in a populationbased sample of patients with diabetes and major depression. Med Care 2004;42:12221229. 